\title{
Receptor-Type Tyrosine-Protein Phosphatase S
}

National Cancer Institute

\section{Source}

National Cancer Institute. Receptor-Type Tyrosine-Protein Phosphatase S. NCI

Thesaurus. Code $\mathrm{C} 124925$.

Receptor-type tyrosine-protein phosphatase S (1948 aa, $217 \mathrm{kDa}$ ) is encoded by the human PTPRS gene. This protein is involved in the dephosphorylation of tyrosine residues. 